\title{
Magneto-Optical Features of Amorphous Ribbon $(\mathrm{CoFe})_{75} \mathrm{Si}_{10} \mathrm{~B}_{15}$
}

\author{
Aida Isayeva \\ Azerbaijan University of Architecture and Construction, Republic of Azerbaijan, (Ph.d student)
}

\begin{abstract}
In the article the optic and magnetic- optical properties of crystalline and amorphous alloys on the bases of Co-Fe were researched. They spectral and consternation dependences was constructed and the mechanism of magnetically optical reaction were revealed.
\end{abstract}

Keywords: amorph ribbon, cristallization, head treatement, Equatorial Kerr effect (EEK), spectral depence, magneto-optical features

\section{Introduction}

It's quite clear that, optical and magneto-optical research methods are sensitive to the surface conditions of the sample [1]. The magneto-optical studies can provide information about the magnetic and electronic structure of the surface layer of the substance, which allows determining its phase state and solving a variety of tasks in the area ofthe surface of magnetic transitions. The penetration depth of light into a substance depends on the wavelength [3], so with the help of the field dependence of magneto-optical effects at different wavelengths can study the magnetic properties of the surface layers of different thickness. Samples:

Amorphous ribbon $(\mathrm{CoFe})_{75} \mathrm{Si}_{10} \mathrm{~B}_{15}$ were prepared by melt quenching, then were annealed in a weak magnetic field at a temperature of $420 \circ \mathrm{C}$ (below the crystallization temperature) in air and in vacuum. The thickness of the amorphous ribbons of the $25 \mu \mathrm{m}$, the length of $10 \mathrm{~mm}$, width of $5 \mathrm{~mm}$. Sample annealing time ranges from 0.25 to 36 hours. The magnetic field during heat treatment was applied along long side of the samples and varied from 50 mOe to 15 Oe.

Table 1: Conditions of heat treatment of amorphous $(\mathrm{CoFe})_{75} \mathrm{Si}_{10} \mathrm{~B}_{15}$

\begin{tabular}{|c|c|c|}
\hline \multicolumn{3}{|c|}{$\begin{array}{c}(\mathrm{CoFe})_{75} \mathrm{Si}_{10} \mathrm{~B}_{15} \text { amorph ribbon } \\
\text { annealed in temperature of } 420^{\circ} \mathrm{C}\end{array}$} \\
\hline \multicolumn{3}{|c|}{ annealed in air } \\
\hline $3 \mathrm{E}$ & $2 \mathrm{E}$ & 8 hour \\
\hline 1 hour & 1 hour & $50 \mathrm{mE}$ \\
\hline 5 hour & 5 hour & $2 \mathrm{E}$ \\
\hline 12hour & 12 hour & $10 \mathrm{E}$ \\
\hline & & $15 \mathrm{E}$ \\
\hline
\end{tabular}

\section{Spectral Dependence of Amorphous Ribbon $(\mathrm{CoFe})_{75} \mathrm{Si}_{10} \mathrm{~B}_{15}$}

Experimental studies were conducted for magneto-optical properties of untreated samples, and annealed in air and in vacuum (Table 1). It has been found that the form of the spectral dependency of EEK for amorphous ribbons is strongly dependent on the heat treatment conditions: temperature and annealing time, the external magnetic field annealing environment. For a series of samples annealed in air at values of the field 2 Oe and 3 Oe, the shape of the spectra and the Kerr effect size changes with increasing annealing time as follows (Fig. 1 (B)).

For ribbons and untreated sample annealed for 20 minutes EEK value increases in incident light energy of 1.5 to 2.5 $\mathrm{eV}$, and starting from $3 \mathrm{eV}$, gradually acquires frequencyindependent form. The results were compared with the known spectral dependences of EEK of Co -based amorphous alloys (Fig. 1 (A)), which are characterized by a broad peak near $3 \mathrm{eV}$. Obviously, compared curves have similar shape and size of the magneto-optical effect [4]. With increasing annealing time EEK spectra of amorphous ribbons are transformed, as evidenced by the appearance of features of the incident light at energies $\mathrm{hv} \sim 1.8 \mathrm{eV}$ and hv $4.5 \mathrm{eV}$. Comparison with typical spectral dependences for Co alloys (fig 1 (A)), we conclude that the Kerr effect annealed in air amorphous ribbons gradually takes the form of inherent microcrystalline alloys of Co (Curves of equatorial Kerr effect of polycrystalline and microcrystalline Co have characteristic differences). EEK curves for samples with an annealing time of 5 hours or more have finally formed a shape characteristic of crystalline alloys of Co [4], as evidenced by the study of the spectral dependences of EEK series amorphous alloys annealed for 8 hours in magnetic fields of various sizes. The spectra EEK such samples were found changes in the amplitude of the MO effect with an increase in the magnetic field during annealing, and the shape of the curves has remained virtually unchanged (Fig. 2 (A)). Spectral dependence of EEK for such ribbons have obvious peculiarity in the area of hv $1.8 \mathrm{eV}$ and $\mathrm{hv} \sim 4.5 \mathrm{eV}$, characteristic for microcrystalline alloys of Co.

It should be noted that the results of direct structural studies, show that the alloy of $(\mathrm{CoFe})_{75} \mathrm{Si}_{10} \mathrm{~B}_{15}$ after annealing at 420 $\circ \mathrm{C}$ is roentgen amorphous [4]. However, changes in the shape and size of the equatorial Kerr effect spectra indicate changes in the microstructure of the annealed samples. The studies of magneto optical properties of these roentgen amorphous ribbons show that the heat treatment in the vicinity of the sample surface is formed and developed sequentially microcrystalline. Note that only the annealing in air leads to a near-surface crystalline layer. 
International Journal of Science and Research (IJSR)

ISSN (Online): 2319-7064

Index Copernicus Value (2013): 6.14 | Impact Factor (2015): 6.391
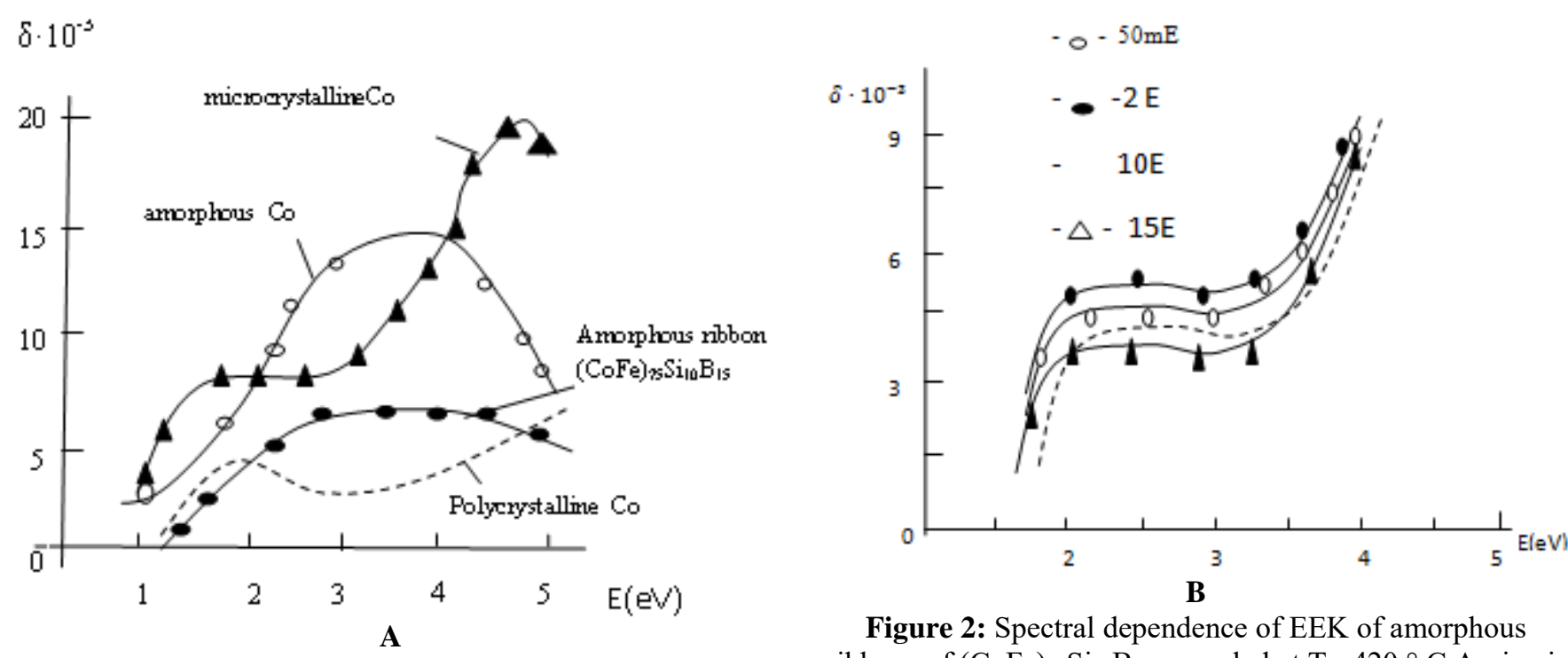

Figure 2: Spectral dependence of EEK of amorphous ribbons of $(\mathrm{CoFe})_{75} \mathrm{Si}_{10} \mathrm{~B}_{15}$ annealed at $\mathrm{T}=420^{\circ} \mathrm{C} \mathrm{A}$ - in air for 8 hours in in various fields; $\mathrm{B}$ - in to vacuum for various times in the two Oe.

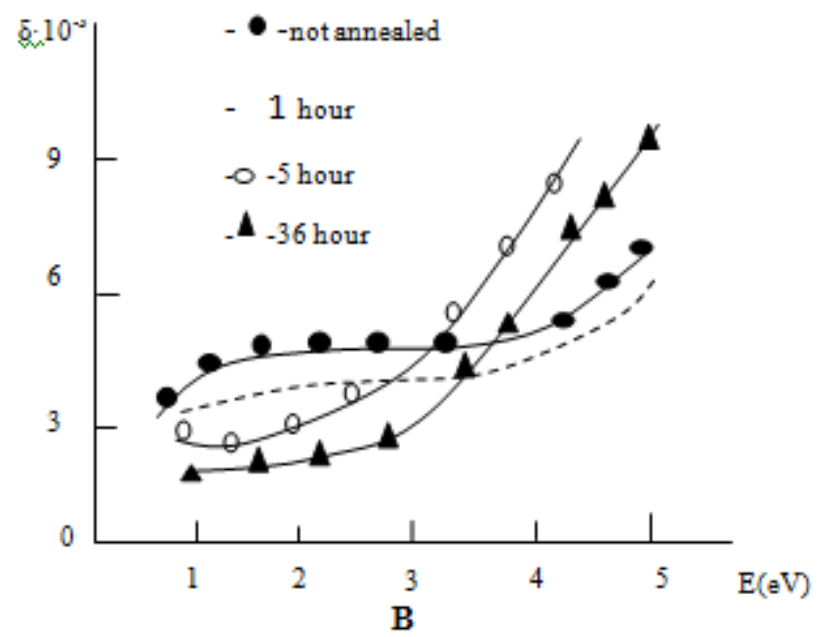

Figure 1: A - typical spectra of EEK Co -based amorphous alloys, poly- and microcrystalline Co [4]; B - EEK spectra of amorphous ribbons annealed in air for two different periods in the field of 2 Oe.

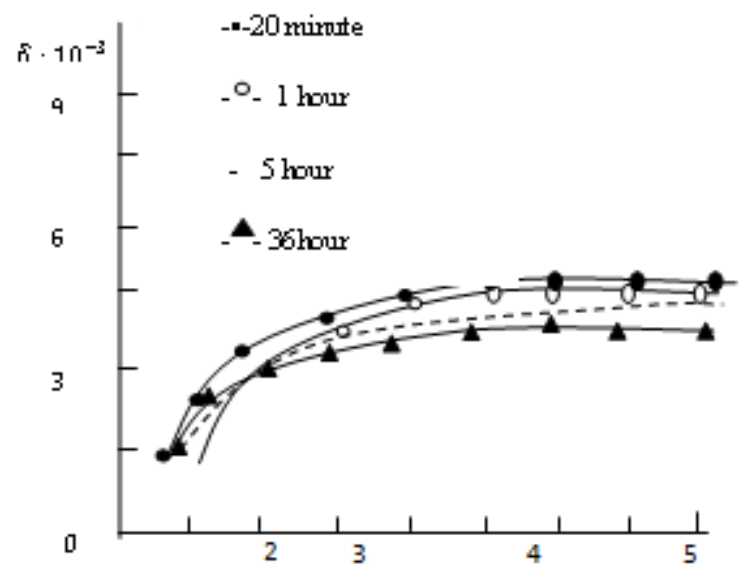

Elev'

A

Any change in spectral dependences of EEC of samples annealed in vacuum, was not observed (Fig.2 (B)). EEK spectra of amorphous ribbons annealed in a vacuum, not change shape with increasing annealing time and, even after the heat treatment within 36 hours, maintained the form, characteristic curves of EEK of Co based amorphous alloys. Note that the behavior of the field curves of magneto impedance is also highly dependent on the conditions of the heat treatment of the samples. While for the samples annealed in air, there is an asymmetric giant magnetic impedance effect profile.

Currently, methods used to study the physical properties of amorphous electronic microcopy, X-ray spectroscopy and diffraction techniques, nail polish-spectroscopy neutron graph, as well as magnetic, optical, and to emphasize the need magneto optical methods. The study of methods of optical and physical properties of amorphous magneto optical lose its relevance today, because the differential method magneto optical methods are sensitive to the direction of the electron spin of spin feels crossings between sub-zones, on the other hand the implementation of this method is cheaper.

In recent years, some of which will find their application in active spintronic learned and highlighted the need to make physical properties. External magnetic field dependence of the electrical resistance of these heterogeneous materials, ferromagnetic or paramagnetic alternating layers of magnetic resistance of the metal and granular structures giant, bib ferromagnetic metals were separated from each other by a layer of dielectric resistance of the magnetic tunnel, ferromagnetic material to the non-magnetic material Spine was polar injection is an example of current carriers.

One of the most important reflection of light Ellipse meter $p$ and $\mathrm{s}$ components of the electromagnetic radiation in relation to each other to learn how to change. P and s components of light falling on the line polarizing after the electromagnetic wave elliptical polarization occur. Note that the optical constants and equatorial Ker effect "of metals and alloys 


\section{International Journal of Science and Research (IJSR) \\ ISSN (Online): 2319-7064}

Index Copernicus Value (2013): 6.14 | Impact Factor (2015): 6.391

physics" laboratory - the established a universal device was measured. For this experimental phases of the recovery and the difference in polarization azimuth $\delta \rho=\mathrm{dp}-\mathrm{ds}$ was determined. Polyarisator for the determination of the parameters - for example - analyze top (PNA) system polyarisator and the analyzer measures the intensity of light in different azimuth. The intensity of light reflected from the sample to the system

$\mathrm{I}(\Psi \mathrm{p}, \Psi \mathrm{A})=\mathrm{Io}(\sin 2 \Psi \mathrm{p} \sin 2 \Psi \mathrm{A}+\rho 2 \cos 2 \Psi \mathrm{p} \cdot \cos 2 \Psi \mathrm{A}+$ $1 / 2 \rho \sin 2 \Psi \mathrm{p} \cdot \sin 2 \Psi \mathrm{A} \cdot \cos \delta)$ attitude is appointed.

The $\Psi \mathrm{p}$ and $\Psi \mathrm{A}$ - polyarisator and azimuth analyzer, azimuth, and polarization $\rho$ and $\delta$ restored, $p$ phase shift between the components.

$\Psi \mathrm{p}= \pm \pi / 4 ; \Psi \mathrm{A}=\pi / 2,0, \pm \pi / 4$ in the case of measuring the intensity they take the following prices:

$\mathrm{I} 1=\mathrm{I}(\Psi \mathrm{p}, \pi / 2) ; \mathrm{I} 2=\mathrm{I}(\Psi \mathrm{p}, 0) ; \mathrm{I} 3=(\Psi \mathrm{p}, \pi / 4) ; \mathrm{I} 4=\mathrm{I}(\Psi \mathrm{p},-$ $\pi / 4)$

The intensity of the polarization $\rho$ and $\delta$ ellipse parameters are calculated.

$\rho=\operatorname{tg} \Psi \mathrm{p} \sqrt{ } \mathrm{I} 2 / \mathrm{I} 1, \operatorname{Cos} \delta=1 / 2(\rho+1 / \rho)(\mathrm{I} 3-\mathrm{I} 4 / \mathrm{I} 3+\mathrm{I} 4)$

These optical constants $\mathrm{n}$ and $\mathrm{k}$ are determined in accordance with:

Formula

$(\mathrm{n} 2-\mathrm{k} 2-\sin 2 \varphi) / \operatorname{tg} 2 \varphi * \sin 2 \varphi=(1+\mathrm{y}) /(1-\mathrm{y})(1-\mathrm{x} 2) /(1+\mathrm{x} 2)$

$2 \mathrm{nk} / \operatorname{tg} 2 \varphi * \sin 2 \varphi=(1+\mathrm{y}) /(1-\mathrm{y})(2 \mathrm{x} /(1+\mathrm{x} 2)$

Here $y=2 \rho \cos \delta /(1+\rho 2), x=2 \rho \sin \delta /(1-\rho 2) \varphi$ - angle of light falling on the sample.

The analyzer control unit is assembled to provide rotation. SDA-7 engine analyzer combined reducer. A metallic outer ring of the analyzer from $45^{\circ}$ over the boards and the analyzer is attached to the face of the two light-emitting diode (option pair) is placed. The metal plate to prevent rotation of the receiver diode cuts the engine stops and the analyzer is rotated $45^{\circ}$. Next to augment the interest of the administration block is used. In other words, after the interval when the relay is activated when the engine is placed on the diagram to connect the engine to the tension again and its binding $45^{\circ}$ angle to the rotating analyzer provides turning.

Output switching element plays the role of the electromagnetic relay. Relay is managed winding it is switching the engine winding system. The use of these unit transformer option pair transmitters on the basis of its economic opportunities compared to devices increases. The smart option is associated with universal intensities gets into a computer program, according to the optical constants and the dielectric components are calculated diagonal tensor. For changing the length of wave Mono-khromotor assembled control unit blocks the other difference is that the pair is option its transmitter generator, the transmitter rows stabilize and increase the frequency generator, which allows the stability of the amorph materials for optical dielectric constants after having known tensor diagonal components $\varepsilon 1=\mathrm{n} 2-\mathrm{k} 2, \varepsilon 2=2 \mathrm{nk}$ spectral dependencies established.

For the calculation of non-diagonal components Dielectric tensor the intensity of the electric vector of light waves in the fall when the plane (P-wave) of the $\mathrm{CO}$ into the $\mathrm{TiO} 2$ matrix consisting of particles of amorph materials samples not exposed to any thermal processing relative to the intensity of light reflected from the magnetic field changes, the price of the equatorial Kerr effect has been studied in two different angle of light falling. E

Equatorial Kerr effect during measurement of the sample is placed between the light poles on electromagnet $\mathrm{P}$ from polarysator through the fall. Strengthening the reflected light signal is divided into two collected. Item changing the intensity of light reflected from the sample changes when a magnetic field, the magnetic field is stable in the absence of item is proportional to the intensity of the reflected light. Pulse frequency modulation amplifier, which is used to feed Electromagnet with the works. This is based on the powerful transistor forcing is key. Electromagnet frequency of 70-80 $\mathrm{Hz}$, and eventually joining the opening and closing transitory light modulation provides the magnetic field flow. Section block "log-antilogarithm" assembled microcircuits are working according to the principle. [5]

Then, using optical direct currents and equatorial Kerr effect of non-diagonal components tensor calculated.

$$
\begin{aligned}
& \delta \mathrm{p} 1=\mathrm{a} 1 \varepsilon \dot{\varepsilon} 1+\mathrm{b} 1 \dot{\varepsilon} 2 \\
& \delta \mathrm{p} 2=\mathrm{a} 2 \dot{\varepsilon} 2+\mathrm{b} 2 \dot{\varepsilon} 2
\end{aligned}
$$

$\mathrm{a} 1, \mathrm{~b} 1$ and $\mathrm{a} 2, \mathrm{~b} 2$ are parameters that correlate optical measurements, optical direct current is appointed.

$\mathrm{a}_{1}=2 \sin \varphi_{1}\left(\mathrm{~A}_{1} /\left(\mathrm{A}_{1}^{2}+\mathrm{B}_{1}^{2}\right)\right) ; \mathrm{b}_{1}=2 \sin \varphi_{1}\left(\mathrm{~B}_{1} /\left(\mathrm{A}_{1}^{2}+\right.\right.$ $\left.\left.\mathrm{B}_{1}^{2}\right)\right)$;

$\mathrm{a}_{2}=2 \sin \varphi_{2}\left(\mathrm{~A}_{2} /\left(\mathrm{A}_{2}^{2}+\mathrm{B}_{2}^{2}\right)\right) ; \mathrm{b}_{2}=2 \sin \varphi_{2}\left(\mathrm{~A}_{2} /\left(\mathrm{A}_{2}{ }^{2}+\right.\right.$ $\left.\left.\mathrm{B}_{2}{ }^{2}\right)\right)$;

$\mathrm{A}_{1}=\varepsilon_{2}\left(2 \varepsilon_{1} \cos ^{2} \varphi_{1}-1\right) ; \mathrm{B}_{1}=\left(\varepsilon_{2}^{2}-\varepsilon_{1}^{2}\right) \cos \varphi_{1}+\varepsilon_{1}{ }^{-}$ $\sin ^{2} \varphi_{1}$

$\mathrm{A}_{2}=\varepsilon_{2}\left(2 \varepsilon_{1} \cos ^{2} \varphi_{2}-1\right) ; \mathrm{B}_{2}=\left(\varepsilon_{2}^{2}-\varepsilon_{1}^{2}\right) \cos \varphi_{2}+\varepsilon_{1}$ $\sin ^{2} \varphi_{2}$;

$\varepsilon_{1}=\mathrm{n}^{2}-\mathrm{k}^{2} ; \varepsilon_{2}=2 \mathrm{nk}$

\section{Conclusion}

Conclusions about the formation of a crystalline surface layer in the amorphous ribbon, which allowed investigating of the spectra of EEK, are confirmed by other, more timeconsuming and expensive experiments. According to the results of the Auger spectroscopy, it is known that in the process of annealing in air with increasing time in the surface layer of the amorphous ribbon metal - metalloid ratio varies considerably [4]. Auger spectra of samples annealed in air, have shown that on the amorphous ribbon surface oxide layer reached by metalloids $(\mathrm{B}, \mathrm{Si})$ is formed $(\mathrm{B}(\mathrm{O})$ and $\mathrm{Si}(\mathrm{O})$ ), which develops a depleted layer of these components. Reduction of metalloid could affect the process of crystallization of the amorphous alloy, lowering its temperature. That is why the development of crystalline phase in the depletion layer of $\mathrm{B}$ and $\mathrm{Si}$ is possible even at an annealing temperature of $420{ }^{\circ} \mathrm{C}$. That is, the magnetooptical investigations and Auger spectroscopy data provide a basis to conclude that the oxidation that occurs during annealing in air greatly affects the crystallization process, 


\section{International Journal of Science and Research (IJSR) \\ ISSN (Online): 2319-7064}

Index Copernicus Value (2013): 6.14 | Impact Factor (2015): 6.391

and also on the composition and magnetic properties of the surface layer of amorphous ribbons.

\section{References}

[1] Knobel and K.R.Pirota, J.Magn.Magn.Mater., 242,33, 2002.

[2] Naik S. R., Rai S., Tiwari M. K., G. S. Lodha G. S.. Structural asymmetry of $\mathrm{Si} / \mathrm{Fe}$ and $\mathrm{Fe} / \mathrm{Si}$ interface in Fe/Si multilayers.// J. Phys. D: Appl. Phys. 41, 115307 (2008). 2.

[3] E. Takeda, N. Todoroki, Y. Kitamoto, M. Abe, M. Inoue, T. Fujii, and K. Arai, "Faraday effect enhancement in Coferrite layer incorporated into one-dimensional photonic crystal working as a Fabry-Pérot resonator," J. Appl. Phys. 87, 6782-6784 (2000).

[4] Giselher Herzer, Modern soft magnets: Amorphous and nano-crystalline materials, Acta Materialia, 2013, p718734

[5] Носков М.М. «Оптические и магнитооптические свойство металлов» Свердловск. УНН АН СССР, 220c, 1983

\section{Author Profile}

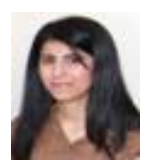

Aida. A. Isayeva is a Ph.D students of Azerbaijan University of Architecture and Construction. She is studing on her doctoral work named "Magnet and magneto optical features of amorph fusion and crystal $(\mathrm{Co}-\mathrm{Fe})_{1-\mathrm{x}} \mathrm{R}_{\mathrm{x}}\left(\mathrm{R}_{\mathrm{x}}=\mathrm{Si} \mathrm{B}\right)$ ". Her specialization is Physics. She is working at Azerbaijan University of Architecture and Construction. 